Article

\title{
Provincial Quality of Economic Growth: Measurements and Influencing Factors for China
}

\author{
Shaofeng Ru ${ }^{1, *}$, Jiaqi Liu ${ }^{1, *}$, Tonghui Wang ${ }^{2}$ and Guo Wei ${ }^{3}$ (I) \\ 1 School of Economics \& Management, Northwest University, Xi'an 710127, China \\ 2 Department of Mathematical Sciences, New Mexico State University, Las Cruces, NM 88003, USA; \\ twang@nmsu.edu \\ 3 Department of Mathematics and Computer Science, University of North Carolina at Pembroke, Pembroke, \\ NC 28372, USA; guo.wei@uncp.edu \\ * Correspondence: rsf00@163.com (S.R.); vickyliu677@163.com (J.L.)
}

Received: 21 January 2020; Accepted: 11 February 2020; Published: 12 February 2020

check for updates

\begin{abstract}
An extended total factor productivity method is developed for measuring the quality of economic growth (QEG). Specifically, criteria for judging the QEG are first elaborated using endogenous economic growth theory, and subsequently, an assessment index system for evaluating QEG is constructed. In this system, the production factors primarily include labor, material capital, education, medical and health, environmental resource, and social security, while the output indexes comprise the gross domestic product (GDP), employment rate, income gap, and environmental pollution. In the empirical study, the directional distance function and Global Malmquist-Luenberger index are implemented to examine the QEG in China from 2000 to 2016 by provinces, regions, and factor decomposition, respectively. The global scale technological change and global pure technological change are the main sources for improving the QEG. The results also reveal a considerable widespread inefficiency and uneven development of the QEG. In general, from the eastern to western to central regions, the QEG becomes noticeably lower; The investment level is not only a driving force for economic growth, but also a source for boosting the QEG. These findings will provide a reference for China in adjusting relevant investments, ameliorating environmental conditions, and accomplishing the unity of quantity, quality, and efficiency in economic growth.
\end{abstract}

Keywords: endogenous economic growth theory; quality of economic growth index; direction distance function; Global Malmquist-Luenberger index

\section{Introduction}

From 1979 to 2010 (32 years), China's economy grew rapidly, with 16 years of growth when the growth rate exceeded $10 \%$. However, since 2012, the economic growth rate has declined. It was $7.8 \%$ in $2012,7.7 \%$ in $2013,7.5 \%$ in $2014,6.9 \%$ in $2015,6.7 \%$ in $2016,6.9 \%$ in 2017 , and $6.6 \%$ in 2018 , respectively. On the other hand, the simple extension of the economic development mode led to overcapacity, high environmental pollution, overall imbalance of economic structure, a widening gap between the rich and poor, and the unstable quality of economic growth (QEG). Therefore, China is currently faced with the dual task of transforming the mode of economic development and improving the quality of economic growth. The spirit of the Central Economic Work Conference in 2013 clearly put the QEG as a top priority. However, the effect of improving the quality of economic growth in various provinces and regions was not obvious. It can be seen that improving the quantity and QEG will be a difficult problem for a long time to come. Hence, the following issues arise. How is the QEG judged? How can one evaluate China's QEG, and what are the main factors affecting the QEG? 
The exploration of these issues is of great significance for transforming the economic development mode and improving the QEG.

At present, there are two kinds of measures popularly used as criteria for judging the QEG: (1) the QEG in a narrow sense, and (2) the QEG in a broader sense. We begin with a review of existing studies employing these two measures.

\section{(1) QEG in a narrow sense}

We often use the total factor productivity (TFP) to measure the QEG in a narrow sense. This is a traditional way to assess the QEG. It is a core indicator for judging the QEG and economic sustainability of a country or an economic entity [1-4]. The TFP is the input-output efficiency of economic growth. Generally, the input indicators contain labor and capital, and the output indicator is the GDP. The advantages of adopting the TFP include:

(a) With the TFP, we can capture the driving force of economic growth and its sources, allowing us to analyze the growth of input factors and the contribution of technological innovation and technological efficiency to economic growth. According to the theory of economic growth, all economic growth is the result of factor growth and technological progress. As long as the factors of production continue to accumulate, the rate of economic growth will be promoted, and technological progress will continue to improve the economy. Therefore, the rate of technological progress in TFP can be used to distinguish between input-type growth and efficiency-based growth, so as to determine the sustainability of economic growth.

(b) The TFP is the basis for formulating and evaluating economic policies. Specifically, by comparing the contribution of TFP growth to economic growth and the contribution of the factor input to economic growth, it can be determined whether economic policy should focus primarily on increasing aggregate demand or mainly on adjusting the economic structure and promoting the total supply of technological innovation. Therefore, the adoption of the TFP to judge the QEG has a certain rationality.

Based on this, many scholars have studied the roles of TFP in measuring China's economic progress [5-15]. However, in their calculation of TFP, only the input constraints on the production factors, e.g., labor and capital, etc., are involved; the influence from other factors on the QEG was ignored. For example, they failed to take into account undesired outputs and allocation effects. As a result, the judgment result would mislead one's interpretation of the TFP [16], distorting the assessment on the change in social welfare, etc.

Hence, in recent years, many scholars turned to study China's economic growth efficiency under environmental constraints. Wang et al. (2010) [17] calculated the environmental efficiency, environmental TFP, and its components for 30 provinces in the period of 1998 to 2007. Wang and Fan (2012) [18] studied the environmental TFP for 30 provinces from 1999 to 2010 under the factors of energy and undesired carbon dioxide emissions. Qi (2013) [19] included energy resource and carbon dioxide in the TFP measurement and decomposition framework, and measured the changes of the environmental efficiency and environmental factor productivity for 29 provinces from 2001 to 2009 . Tu and Liu (2011) [20] conducted an empirical analysis of China's environmental efficiency under the constraints of resources and environment from 1998 to 2008. Clearly, these studies are an improvement and development of the assessment of the QEG in terms of the TFP.

However, using the TFP alone to judge the QEG has some limitations, as discussed below. (i) The TFP measures the current input and output, but the fixed asset investment used in the calculation of the TFP has a long-term utility, which is difficult to fully reflect in the present TFP calculation. It is precisely because of this reason that the TFP estimated by many scholars for China differs greatly [21]. (ii) It is easier to cause a logical confusion when using the TFP alone to judge the QEG. Some scholars only use the contribution of the TFP to economic growth as the judgment standard of the economic growth mode, i.e., the low contribution of TFP economic growth equals to an extensive economic development mode and the high contribution of the TFP to economic growth equals to an intensive economic 
development mode. Obviously, the above-stated conclusion obtained only from the contribution of the TFP to economic growth studies has ignored the structure of factor investment.

In fact, according to the endogenous economic growth theory, whether driven by factor input or technological innovation, the source of both is identical: the investment. The difference lies merely in the structure, quality, and capital accumulation of the investment. That is to say, it is difficult to reflect the efficiency of factor allocation when using the TFP to judge the QEG [22].

\section{(2) QEG in a broader sense}

Such a judgment method not only pays attention to the efficiency of economic growth, but also integrates the environmental cost of economic growth, income distribution, social welfare, and the stability of the economic operation into the evaluation of the QEG. The QEG, as a supplement to the speed of economic development, is considered one of the key components of the economic growth process, such as the distribution of opportunities, environmental sustainability, global risk management, and governance structure [23]. Barro (2002) [24] treated the QEG as a factor of social, political, and religious areas, including the level of education, life expectancy, health status, the degree of development of law and order, and the degree of equality in income distribution. Liu (2007) [25] found that the QEG lies in the stability of economic growth, the sustainability of the economic growth mode, the coordination of the economic growth structure, and the harmony of economic growth effects. Additionally, the QEG lies in the stability of economic growth, the efficiency of growth, structural optimization, stability improvement, welfare distribution improvement, and innovation capability [26,27]. In Chao and Xi (2009) [28], the QEG was defined as an economic aspect closely related to economic growth, including the structure stability, welfare change of economic growth, and the distribution of profits, as well as resource utilization and ecological environmental costs.

The above research assesses the QEG from a broader sense using a normative value judgment. However, there still are some shortcomings: (i) The extension is too broad. Various factors beyond the QEG are also included in the evaluation scope, making it impossible to determine the concept of the QEG. (ii) According to the existing definition, a quantitative judgment of the QEG cannot be made, because the quality itself has two meanings: one is used to describe the pros and cons of the objects, and the other refers to the nature and characteristics of the objects. Clearly, if the nature and characteristics are not to be characterized, then the pros and cons cannot be recognized. (iii) When compared to the TFP, it's the failure to analyze the driving force and source of the QEG that renders it merely a simple calculation without economic significance.

In the empirical research on the QEG in a broader sense, researchers mostly construct an index system and then utilize it to obtain a comprehensive measurement of QEG. The controversy of this approach lies in the design of the evaluation index system and the synthetic normalization method of the basic indicators. In recent years, authors who adopted this assessment approach include: Liu and Zhang (2006) [29], Zhao et al. (2006) [30], Ma and Shen (2007) [31], and Chao and Ren (2011) [32]. They mostly employed factor analysis, the relative index method, and principal component analysis. The general idea of these studies is to assign an appropriate weight to each basic indicator based on their respective index systems that are used to assess the QEG, and then to simply add them up to form an index measuring the QEG. Such a result, which can only be considered as a measure of the importance of the total indicator, does not reflect the inherent law of the QEG, nor the technical efficiency of the influencing factors. In fact, economic growth is composed of input factors and their mutual interactions. Structural changes between economic growth production factors constitute the driving force of economic growth. When the ratios between the quantities of production factors are coordinated and the technical efficiency is continuously improved, this will lead to a trend of improved QEG.

In addition, in the above studies, the assessment index systems involve a positive index, inverse index, and moderate index. The processing of the inverse index usually takes the form of a reciprocal, which is obviously unreasonable. The asymmetrical processing of the undesired output and desired 
output, without accounting for the resources and environmental costs in the QEG, would artificially exaggerate the economic returns, which would inevitably lead to a significant reduction in the actual national welfare, thus misleading policy recommendations [33].

In summary, the current research has the following shortcomings when assessing the QEG: (1) In a narrow sense, the use of TFP alone measures merely a single output. Although some studies have considered the undesired outputs, they failed to deliberate critical output indicators such as the income gap between urban and rural areas, and the employment status; (2) In a broader sense, using the indicator system method to measure the QEG cannot reveal the driving source of the change in the QEG; and (3) whether in a narrow or a broader sense, the existing methods for measuring the QEG only consider the total amount of investment, but not the structure of investment. To overcome these drawbacks, we propose an improvement solution in this study.

\section{Motivation to Solve the Problem:}

We propose an extended TFP method to measure the QEG based on the endogenous economic growth theory. For judging the QEG of China, we must consider the following points:

(a) First, the judgment criteria of the QEG should be determined by utilizing the relevant theory and principles on economic growth. The endogenous economic growth theory includes two aspects: On the one hand, the knowledge, as an independent production factor, was contained in the economic growth model established by Romer (1986) [34]. According to Romer, the increase of knowledge can boost the output, economic growth has long-term effects, the increase of knowledge has a positive externality, and the marginal cost of providing knowledge is low. Countries that have been on a low-level growth path for a long time demonstrate poorer investment in the knowledge production sector and a lower rate of technological innovation. Therefore, investment in knowledge production should be encouraged.

On the other hand, the difference in human capital, even for those with the same knowledge, could lead to different economic growth following Lucas' human capital model. The accumulation of human capital is mainly achieved through education, and the human capital has a positive externality and competitiveness. Yi et al. [9] suggested that investment in education and learning should be encouraged to accumulate more human capital to accomplish sustained economic growth. Therefore, the judgment of the QEG cannot be measured in terms of the capital and labor factor input in a general way. The human capital accumulation, knowledge production sector, and human capital investment must be taken into account.

(b) Second, the judgment of the QEG must take into account the total cost of economic growth. Since the process of economic growth determines that this process is subject to costs such as additional labor and materials, improving the QEG can only reduce the total cost of economic growth to a certain minimum, and cannot completely eliminate this cost. Therefore, the QEG can be considered as economic growth under low costs. From this conceptual category, the QEG should minimize the economic and social costs while promoting economic growth.

(c) Finally, according to the theory of economic growth, all economic growth is the result of factor growth and technological progress. First, there must be an accumulation of capital, technological progress, and innovation, the results of investment. China has a latecomer advantage in its way of choosing technological progress. Technological progress can be achieved by purchasing equipment and technology patents embedded in capital investment so as to improve the efficiency of the QEG. At present, a main problem for China's economic growth is not the scale of investment, but the imbalance of the investment structure, such as insufficient long-term public investments and low investments in environmental governance. Therefore, the investment structure should be considered when judging the QEG, and subsequently a unified realization of the quantity and benefit of economic growth will be achieved.

The extended TFP method for measuring the QEG also considers the input-output efficiency of economic growth, such as the traditional measurement of the TFP. However, the difference lies in the 
new understanding of the input and output which are redefined: The input includes labor, material capital, education, medical and health sectors, environmental resources, and social security, and the output contains the effect of economic development, such as the quantitative indicators of the GDP and the employment rate, income gap, and environmental pollution.

The structure of the remainder of the paper is as follows. In Section 2, a comprehensive index system for evaluating the QEG in terms of inputs and outputs is constructed. In Section 3, the Global Malmquist-Luenberger (GML) index method for measuring the QEG is proposed. In Section 4, the quality of the economic growth index (QEGI) for the 30 provinces in China are calculated respectively. Subsequently, the calculated QEGI is decomposed to reflect the influencing factors for the quality change of economic growth. In Section 5, the conclusions, policy implications, research limitations, and future research are presented.

\section{Quality of Economic Growth: Constructing a Comprehensive Evaluation Index System}

Regarding the establishment of an evaluation index system on the QEG, there is still no recognized theoretical system. Based on the existing research, we propose an index system to fill the gap. This system is developed from the endogenous economic growth theory and incorporates several carefully selected input and output indicators.

\subsection{Input Indicators}

In existing studies, input factors of economic growth refer to the quantitative inputs of materials, and these include labor inputs and material capital investments. In our study, we continue to adopt this model, but we further refine the investment structure into: education, medical and health sectors, environmental resource, and social security.

(i) Education investment is human capital, and it is the quality investment of labor. Education investment is not only important to the future development of individuals, but it is also critical to the improvement of the overall quality of all citizens, as well as for social civilization and progress. If the education investment is lower, it will not only reduce the reserve level of human capital but also affect scientific and technological innovation and cultural inheritance, making the economic growth a rootless increase. Therefore, the education input is selected in our evaluation system. The education input is measured via the ratio of education expenditure to fiscal expenditure.

(ii) The medical and health sector is public welfare, not only essential to the health quality of the whole nation and the improved quality of life of people, but also an important guarantee for sustained economic and social development. The input of the medical and health sector is measured as the number of medical and health professionals, and the proportion of medical and health expenditures in fiscal expenditure.

(iii) Environmental resource consumption can promote economic growth. In recent years, people have been more concerned about the efficiency of resource consumption and the cost of environmental pollution. If the resource consumption efficiency and pollution control investment are neglected, the resource depletion and the quality of environmental service functions are degraded. The economic growth under the costs of heavier environmental pollution and stronger ecological destruction is regarded as a growth without future. Therefore, the environmental resource input is included in the evaluation of the QEG, and the relevant indicators are the energy consumption and the total investment of pollution control.

(iv) Harmony, stability, and security together constitute a safe economic environment. If the social security becomes much poorer, investment risks will naturally increase, investment costs will go up, the public's investment enthusiasm will decrease, and the public's satisfaction regarding social and economic development will be negatively impacted. Hence, social security is selected in our evaluation of the QEG, and it is measured as the proportion of public security investment in the fiscal expenditure. 


\subsection{Output Indicators}

The output of economic development measures the result of economic growth, not only in view of the quantity of economic growth, but also in view of the QEG. The 2007 National Public Environmental Awareness Survey Report, released by the Institute of Social Sciences of the Chinese Academy of Social Sciences and the China Environmental Awareness Project Group, pointed out that the public's attention to the QEG relates to the issues of medical care, employment, income gap, and environmental pollution. Therefore, in this paper, the employment rate, income gap, and environmental pollution are used as outputs to measure the QEG. The employment rate is the driving force for economic growth, and it not only measures the QEG but also positively impacts the stability of society. The economic progress sharing plan should be measured primarily by using the variation of the distribution, which in China is recognized through the gap between urban cities and rural areas. Hence, we will adopt, as in the existing literature, the relative ratio incomes between urban cities and rural areas to capture the gap in the income distribution.

In the existing research, the environmental conditions under economic growth are detected in terms of the emissions of $\mathrm{COD}, \mathrm{SO}_{2}$, and $\mathrm{CO}_{2}$. Since $\mathrm{SO}_{2}$ is the main air pollution gas, we choose the $\mathrm{SO}_{2}$ emission as an undesired output. See Table 1 for details of input/output indicators.

Table 1. Definition of indicators.

\begin{tabular}{|c|c|c|}
\hline & Indicator & Definition \\
\hline \multirow{8}{*}{ Input } & Labor & Total number of social workers at the end of the year ( 10,000 people). \\
\hline & Material capital & $\begin{array}{l}\text { The material capital stock calculated by the perpetual inventory } \\
\text { method ( } 100 \text { million yuan). }\end{array}$ \\
\hline & Education & Education expenditure as a proportion of fiscal expenditure (\%). \\
\hline & \multirow{2}{*}{ Medical and health } & Number of medical practitioners (10,000 people). \\
\hline & & Health care expenditure as a share of fiscal expenditure (\%). \\
\hline & \multirow{3}{*}{$\begin{array}{l}\text { Environmental resource } \\
\text { Social security }\end{array}$} & Total energy consumption (million tons of standard coal). \\
\hline & & Total industrial pollution treatment investment divided by GDP (\%). \\
\hline & & Public security expenditure as a share of fiscal expenditure (\%). \\
\hline \multirow{4}{*}{ Output } & Real GDP & Output nominal GDP divided by GDP deflator (100 million yuan). \\
\hline & Employment rate & $\begin{array}{l}\text { Total number of social workers at the end of the year divided by } \\
\text { total population }(\%) \text {. }\end{array}$ \\
\hline & Income gap & $\begin{array}{l}\text { The income of urban residents minus the income of rural residents, } \\
\text { divided by the income of rural residents }(-) \text {. }\end{array}$ \\
\hline & Environmental pollution & $\mathrm{SO}_{2}$ emissions $(10,000$ tons $)$ \\
\hline
\end{tabular}

\section{Models for Measuring the Quality of Economic Growth}

The primary methods for measuring the production efficiency include the Malmquist-Luenberger (ML) productivity index method and the GML index method. The ML index method has the following defects: (1) When the ML index is used to measure the inter-temporal directional distance function, it faces a potential problem: the linear programming problem may not have a solution; (2) The ML index expressed in geometric mean form does not hold circularity or transitivity; and (3) When using two adjacent ML indices to measure the growth of productivity, the calculated TFP index alters the production frontier envelop of the adjacent period, and hence it is impossible to observe the long-term growth trend of the technological progress efficiency. Its economic interpretation may misguide policy-makers by providing misleading interventions in boosting productivity. Oh (2010) [35] combined the Global Malmquist productivity concept with a directional distance function to construct an alternative to the ML index, known as the GML index. This method not only solves the problems of multi-output, multi-input, and undesired output, but also avoids the problem that the linear programming of the traditional ML index has no a solution. At the same time, this index can be cyclically multiplied, avoiding the possibility of an inward shifting of the production front and thereby preventing the faked improvement of technical efficiency. 


\subsection{DEA Model: Containing a Production Set of Undesired Outputs}

A Data Envelopment Analysis (DEA) model is employed to empirically measure the productive efficiency of decision-making units (DMUs). Suppose that there are $K$ DMUs, each DMU having $N$ inputs, $\mathbf{x}=\left(x_{1}, x_{2}, \cdots, x_{N}\right) \in R_{+}^{N}, M$ expected outputs, $\mathbf{y}=\left(y_{1}, y_{2}, \cdots y_{M}\right) \in R_{+}^{M}$, and $J$ undesired outputs, $\mathbf{b}=\left(b_{1}, b_{2}, \cdots, b_{J}\right) \in R_{+}^{J}$. Assume $\sum_{k=1}^{K} b_{j}^{k}>0, \sum_{j=1}^{J} b_{j}^{k}>0$, where $x^{k, t}, y^{k, t}, b^{k, t}$ denote, respectively, the inputs and outputs at time $t=1, \cdots, T$ for the $k$ th $(k=1, \cdots, K)$ province.

The current production technology set is:

$$
P^{t}\left(\mathbf{x}^{t}\right)=\left\{\left(\mathbf{x}^{t}, \mathbf{y}^{t}, \mathbf{b}^{t}\right)\right\}, \mathbf{x}^{t} \in R_{+}^{N}, t=1,2, \cdots, T, \mathbf{x}^{t} \text { can produce }\left(\mathbf{y}^{t}, \mathbf{b}^{t}\right)
$$

Here, $P^{t}\left(\mathbf{x}^{t}\right)$ is a bounded closed convex set. The input and expected output are highly disposable, that is, if $\left(\mathbf{x}^{t}, \mathbf{y}^{t}, \mathbf{b}^{t}\right) \in P^{t}\left(\mathbf{x}^{t}\right)$ and $\mathbf{x}^{\prime t} \geq \mathbf{x}^{t}$ or $\mathbf{y}^{\prime t} \leq \mathbf{y}^{t}$, then $\left(\mathbf{x}^{\prime}, \mathbf{y}^{t}, \mathbf{b}^{t}\right) \in P^{t}\left(\mathbf{x}^{t}\right)$ or $\left(\mathbf{x}^{t}, \mathbf{y}^{\prime t}, \mathbf{b}^{t}\right) \in P^{t}\left(\mathbf{x}^{t}\right)$.

In addition, according to Fare et al. (1994) [36], two assumptions are required for dealing with undesirable outputs, that is, the weak disposability of the outputs axiom and expected output and the undesired output zero combination axiom.

Axiom 1 (Weak disposability axiom 1): If $\left(\mathbf{x}^{t}, \mathbf{y}^{t}, \mathbf{b}^{t}\right) \in P^{t}\left(\mathbf{x}^{t}\right)$ and $0 \leq \theta \leq 1$, then $\left(\mathbf{x}^{t}, \theta \mathbf{y}^{t}, \theta \mathbf{b}^{t}\right) \in P^{t}\left(\mathbf{x}^{t}\right)$.

This axiom means that if the undesired output is to be reduced, the expected output must be reduced at the same time, indicating that the improved environment and the pollution reduction is costly so that the idea of environmental regulation should be included into the analytical framework.

Axiom 2 (Zero combination axiom 2): If $\left(\mathbf{x}^{t}, \mathbf{y}^{t}, \mathbf{b}^{t}\right) \in P^{t}\left(\mathbf{x}^{t}\right)$ and $\mathbf{b}^{t}=0$, then $\mathbf{y}^{t}=0$.

This axiom means that if there is no undesired output, then there is no expected output. In other words, whenever an expected output is produced, the undesirable output accompanies concurrently. In this axiom, environmental factors have been brought into the analytical framework.

Definition of global production technology set: $P^{G}(\mathbf{x})=P^{1}\left(\mathbf{x}^{1}\right) \cup P^{2}\left(\mathbf{x}^{2}\right) \cup \cdots \cup P^{T}\left(\mathbf{x}^{T}\right)$, a global production technology set, is constructed by utilizing the data obtained over the entire time period. All DMUs are compared with the production frontier of the global production technology set, which enhances the comparability between the technical efficiencies of DMUs.

Using the DEA approach, under the condition of constant returns to scale, the production technology model that satisfies the above axioms is given by:

$$
P^{t}\left(\mathbf{x}^{t}\right)=\left\{\begin{array}{l}
\left(\mathbf{y}^{t}, \mathbf{b}^{t}\right): \sum_{k=1}^{K} z_{k}^{t} y_{k m}^{t} \geq y_{m}^{t}, m=1, \cdots, M ; \\
\sum_{k=1}^{K} z_{k}^{t} b_{k j}^{t}=b_{j}^{t}, j=1, \cdots, J ; \sum_{k=1}^{K} z_{k}^{t} x_{k n}^{t} \leq x_{n}^{t}, \quad n=1, \cdots, N ; z_{k}^{t} \geq 0, k=1, \cdots, K
\end{array}\right\}
$$

\subsection{Global Malmquist-Luenberger (GML) Index Method}

The global directional distance function is $\vec{D}_{o}^{G}\left(x^{\tau}, y^{\tau}, b^{\tau} ; g^{\tau}\right)=\max \left\{\beta:\left(y^{\tau}, b^{\tau}\right)+\beta g^{\tau} \in P^{G}\left(x^{\tau}\right)\right\}$, where $\tau=t, t+1, P^{G}\left(x^{\tau}\right)$ denotes the global production possible set, and $\mathbf{g}=(\mathbf{y},-\mathbf{b})$ is the directional vector. We adopt the definition of the GML index given in Tao and Qi (2012) [37], under the constant returns to scale:

$$
G M L_{t}^{t+1}=\frac{1+\vec{D}_{o}^{G}\left(x^{t}, y^{t}, b^{t} ; y^{t},-b^{t}\right)}{1+\vec{D}_{o}^{G}\left(x^{t+1}, y^{t+1}, b^{t+1} ; y^{t+1},-b^{t+1}\right)} .
$$

Let:

$$
S(\mathbf{x}, \mathbf{y}, \mathbf{b} ; \mathbf{g})=1+D(\mathbf{x}, \mathbf{y}, \mathbf{b} ; \mathbf{g})
$$


Then, it holds that:

$$
S_{i}^{j}\left(\mathbf{x}^{\tau}, \mathbf{y}^{\tau}, \mathbf{b}^{\tau} ; \mathbf{y}^{\tau},-\mathbf{b}^{\tau}\right)=1+D_{i}^{j}\left(\mathbf{x}^{\tau}, \mathbf{y}^{\tau}, \mathbf{b}^{\tau} ; \mathbf{y}^{\tau}-\mathbf{b}^{\tau}\right),
$$

where $D_{i}^{j}\left(\mathbf{x}^{\tau}, \mathbf{y}^{\tau}, \mathbf{b}^{\tau} ; \mathbf{y}^{\tau}-\mathbf{b}^{\tau}\right)$ is the directional distance function under the return $i, \tau$ and is the time period before the time $j, i=C, V ; j=t, t+1, G ; \tau=t, t+1, C$ is the constant return, and $V$ is the variable return. Therefore, the GML index is partitioned as following:

$$
\begin{aligned}
& G M L_{t}^{t+1}=\frac{\overrightarrow{S_{c}^{G}}\left(x^{t}, y^{t}, b^{t} ; y^{t},-b^{t}\right)}{\overrightarrow{S_{c}^{G}}\left(x^{t+1}, y^{t+1}, b^{t+1} ; y^{t+1},-b^{t+1}\right)} \\
& =\left(\frac{\overrightarrow{S_{V}^{t}}\left(x^{t}, y^{t}, b^{t} ; y^{t},-b^{t}\right)}{\overrightarrow{S_{V}^{t+1}\left(x^{t+1}, y^{t+1}, b^{t+1} ; y^{t+1},-b^{t+1}\right)}}\right) \times\left(\frac{\overrightarrow{S_{V}^{G}}\left(x^{t}, y^{t}, b^{t} ; y^{t},-b^{t}\right) / \overrightarrow{S_{V}^{t}}\left(x^{t}, y^{t}, b^{t} ; y^{t},-b^{t}\right)}{\overrightarrow{S_{V}^{G}}\left(x^{t+1}, y^{t+1}, b^{t+1} ; y^{t+1},-b^{t+1}\right) / \overrightarrow{S_{V}^{t+1}}\left(x^{t+1}, y^{t+1}, b^{t+1} ; y^{t+1},-b^{t+1}\right)}\right) \\
& \times\left(\frac{\overrightarrow{S_{C}^{G}}\left(x^{t}, y^{t}, b^{t} ; y^{t},-b^{t}\right) / \vec{S}_{V}^{G}\left(x^{t}, y^{t}, b^{t} ; y^{t},-b^{t}\right)}{\overrightarrow{\overrightarrow{S_{C}^{t}}}\left(x^{t}, y^{t}, b^{t} ; y^{t},-b^{t}\right) / \vec{S}_{V}^{t}\left(x^{t}, y^{t}, b^{t} ; y^{t},-b^{t}\right)} \times \frac{\overrightarrow{S_{C}^{+1}}\left(x^{t+1}, y^{t+1}, b^{t+1} ; y^{t+1},-b^{t+1}\right) / \vec{S}_{V}^{\vec{S}+1}\left(x^{t+1}, y^{t+1}, b^{t+1} ; y^{t+1},-b^{t+1}\right)}{\overrightarrow{S_{C}^{G}}\left(x^{t+1}, y^{t+1}, b^{t+1} ; y^{t+1},-b^{t+1}\right) / \vec{S}_{V}^{G}\left(x^{t+1}, y^{t+1}, b^{t+1} ; y^{t+1},-b^{t+1}\right)}\right) \\
& \times\left(\frac{\overrightarrow{S_{C}^{t}}\left(x^{t}, y^{t}, b^{t} ; y^{t},-b^{t}\right) / \overrightarrow{S_{V}^{t}}\left(x^{t}, y^{t}, b^{t} ; y^{t},-b^{t}\right)}{\overrightarrow{S_{C}^{t+1}\left(x^{t+1}, y^{t+1}, b^{t+1} ; y^{t+1},-b^{t+1}\right) / S_{V}^{t+1}\left(x^{t+1}, y^{t+1}, b^{t+1} ; y^{t+1},-b^{t+1}\right)}}\right)
\end{aligned}
$$

which is equivalent to the product of the following terms:

$$
G M L_{t}^{t+1}=G P E C_{t}^{t+1} \times G P T C_{t}^{t+1} \times G S E C_{t}^{t+1} \times G S T C_{t}^{t+1} .
$$

The GML index is decomposed into four parts: global pure efficiency change (GPEC), global pure technological change (GPTC), global scale efficiency change (GSEC), and global scale technological change (GSTC). The first one, GPEC $t+1$, is the change in global pure efficiency change, indicating how close a DMU approaches the global production frontier between the period $t$ and the period $t+1$. If $\operatorname{GPEC}_{t}^{t+1}>(<) 1$, the DMU is moving toward the frontier (or away from the frontier) so that the efficiency of production activities is improving (or deteriorating). The second item, GPTC $C_{t}^{t+1}$ is used to measure the movement of the production frontier as the technical progress, describing the closeness of the current technology frontier to the global technology frontier. If $\mathrm{GPTC}_{t}^{t+1}>(<) 1$, the production frontier of the current period gets closer to (or away from) the global production frontiers, reflecting the technological progress (or technical retrogression). The third term, $G S E C_{t}^{t+1}$ expresses a change in the scale efficiency. If $G_{S E C}^{t+1}>(<) 1$, an increase (or decrease) in the scale efficiency occurs. The fourth term, $\operatorname{GSTC}_{t}^{t+1}$ measures the global scale technological change. If $\mathrm{GSTC}_{t}^{t+1}>(<) 1$, the technology deviates from constant returns to scale (or moves toward constant returns to scale). The TFP index indicates the movement of DMUs to the optimal production-practice frontier and the production frontier. If $G M L_{t}^{t+1}>1$, the TFP is increased; Otherwise, it is reduced.

\subsection{Calculating Global Directional Distance Function}

In order to measure and decompose the GML index, it is necessary to use the linear programming method to calculate four directional distance functions with constant returns to scale and variable returns to scale, respectively. With constant returns to scale, we utilize the observations of periods $t$ and $t+1$ and the production frontier to compute $\vec{D}_{o}^{t+1}\left(\mathbf{x}^{t+1}, \mathbf{y}^{t+1}, \mathbf{b}^{t+1} ; \mathbf{y}^{t+1},-\mathbf{b}^{t+1}\right)$ and $\vec{D}_{o}^{t}\left(\mathbf{x}^{t}, \mathbf{y}^{t}, \mathbf{b}^{t} ; \mathbf{y}^{t},-\mathbf{b}^{t}\right)$, and we apply the observations in periods $t$ and $t+1$ and the global production frontier to compute $\vec{D}_{o}^{G}\left(\mathbf{x}^{t}, \mathbf{y}^{t}, \mathbf{b}^{t} ; \mathbf{y}^{t},-\mathbf{b}^{t}\right)$ and $\vec{D}_{o}^{G}\left(\mathbf{x}^{t+1}, \mathbf{y}^{t+1}, \mathbf{b}^{t+1} ; \mathbf{y}^{t+1},-\mathbf{b}^{t+1}\right)$. The specific calculation requires a linear programming model. For example, for the $t$ th period, the $r$ th directional distance function of the current decision unit can be obtained by solving the following linear programming: 


$$
\begin{aligned}
& D_{0}^{t}\left(\mathbf{x}^{t}, \mathbf{y}^{t}, \mathbf{b}^{t} ; \mathbf{y}^{t},-\mathbf{b}^{t}\right)=\max \beta \\
& \text { s.t. } \sum_{k=1}^{K} z_{k}^{t} y_{m}^{k, t} \geq(1+\beta) y_{m}^{r, t}, m=1, \cdots, M \\
& \\
& \sum_{k=1}^{K} z_{k}^{t} b_{j}^{k, t}=(1-\beta) b_{j}^{r, t}, j=1, \cdots, J \\
& \sum_{k=1}^{K} z_{k}^{t} x_{n}^{k, t} \leq(1-\beta) x_{n}^{r, t}, n=1, \cdots, N \\
& z_{k}^{t} \geq 0, \quad k=1, \cdots, K
\end{aligned}
$$

The $t$ th global directional distance function solution model is shown below:

$$
\begin{aligned}
& D_{0}^{G}\left(\mathbf{x}^{t}, \mathbf{y}^{t}, \mathbf{b}^{t} ; \mathbf{y}^{t},-\mathbf{b}^{t}\right)=\max \beta \\
& \text { s.t. } \sum_{t=1}^{T} \sum_{k=1}^{K} z_{k}^{t} y_{m}^{k, t} \geq(1+\beta) y_{m}^{r, t}, m=1, \cdots, M \\
& \\
& \quad \sum_{t=1}^{T} \sum_{k=1}^{K} z_{k}^{t} b_{j}^{k, t}=(1-\beta) b_{j}^{r, t}, j=1, \cdots, J \\
& \quad \sum_{t=1}^{T} \sum_{k=1}^{K} z_{k}^{t} x_{n}^{k, t} \leq(1-\beta) x_{n}^{r, t}, n=1, \cdots, N \\
& \quad z_{k}^{t} \geq 0, \quad k=1, \cdots, K
\end{aligned}
$$

\section{Evaluation and Factor Decomposition of QEG}

In our study, economic data from 30 provinces in China, from the year 2000 to the year 2016, were collected. The specific publications included the Statistical Collection of Sixty Years of New China and the China Statistical Yearbook. Due to the data availability, the sample did not include the Tibet Autonomous Region, Hong Kong, Macao, and Taiwan regions. Missing data were supplemented by calculating the average growth rate of existing data. The software program MatLab-2016a was selected to calculate the distance functions given in Models (8) and (9). The GML index was utilized to compute the TFP index of economic growth, and this calculation result will be referred as the quality of economic growth index (QEGI).

\subsection{Data Description}

\subsubsection{The Input Indicators of the QEG Are Explained as Follows}

(1) Labor input: It is defined as the total number of employed people at the end of the year. In order to avoid duplicate counting of input, labor input does not include the number of medical practitioners.

(2) Material capital input: It is defined as tangible, man-made goods to be used to create a product or service. The currently widely used perpetual inventory method is employed to calculate the physical capital stock of each region. The formula for estimating the physical capital stock is $K_{i t}=K_{i t-1}\left(1-\delta_{i t}\right)+I_{i t}$, where $i$ refers to the $i$ th region and $t$ refers to the year. The economic depreciation rate that is used is $10.96 \%$ [38]. We first convert the fixed capital of each calendar year to the constant price value of the year 2000 according to the fixed asset investment price index of each region, and then estimate the physical capital stock of each calendar year based on the set depreciation rate and the base period capital stock.

(3) Education input: This is the proportion of education expenditure in the total fiscal expenditure.

(4) Medical and health input: The number of medical and health practitioners and the ratio of the medical health expenditure to the total fiscal expenditure are used as the medical and health input.

(5) Environmental resource input: This is recognized through the total energy consumption. The environmental pollution treatment refers to the intensity of the industrial pollution treatment, that is, the total industrial pollution treatment investment divided by the GDP.

(6) Social security input: It is the public security expenditure as a proportion of the fiscal expenditure. 


\subsubsection{The Output Indicators of QEG Are Explained as Follows}

(1) Real GDP: Calculate the GDP deflator based on the GDP index published in the China Statistical Yearbook first, and then compute the product of the GDP deflators of all periods. Adopting the fixed base index in 2000, the real GDP is obtained by dividing the nominal GDP by the GDP deflator.

(2) Employment rate: It is defined by dividing the number of employed people by the total labor force, and multiplying this number by 100.

(3) Income gap: It is defined as the relative income gap between urban and rural areas: It is obtained by first subtracting the income of rural residents from the income of urban residents and dividing it by the income of rural residents.

(4) Environmental pollution: It is calculated by the total $\mathrm{SO}_{2}$ emissions over the years for each province or region.

\subsection{Measurement of QEGI in China}

According to the linear programming models (8) and (9), under variable returns to scale and the weak disposability of undesired output, the GML index was used to calculate the changes in China's QEGI from 2000 to 2016, and furthermore it was decomposed into four parts: GPEC, GPTC, GSEC, and GSTC. The QEGI reflects the overall level of the QEG, and the decomposition can reflect the internal mechanism in improving the QEG. The specific results are shown in Table 2 and Figure 1.

Table 2. China's QEGI and decomposition from 2000 to 2016.

\begin{tabular}{cccccc}
\hline Year & QEGI & GPEC & GPTC & GSEC & GSTC \\
\hline 2000 & 1.000 & 1.000 & 1.000 & 1.000 & 1.000 \\
2001 & 0.956 & 1.000 & 0.993 & 1.000 & 0.963 \\
2002 & 1.055 & 1.000 & 1.005 & 1.000 & 1.050 \\
2003 & 1.037 & 1.000 & 1.008 & 0.969 & 1.062 \\
2004 & 1.086 & 1.000 & 1.007 & 1.032 & 1.045 \\
2005 & 1.031 & 1.000 & 1.018 & 1.000 & 1.013 \\
2006 & 0.998 & 1.000 & 1.013 & 1.000 & 0.985 \\
2007 & 1.088 & 1.000 & 0.998 & 1.000 & 1.090 \\
2008 & 1.012 & 1.000 & 1.021 & 0.983 & 1.007 \\
2009 & 1.043 & 1.000 & 1.008 & 0.947 & 1.093 \\
2010 & 1.056 & 1.000 & 1.025 & 0.924 & 1.116 \\
2011 & 1.043 & 1.000 & 1.024 & 0.970 & 1.050 \\
2012 & 1.055 & 0.784 & 1.308 & 0.802 & 1.222 \\
2013 & 1.056 & 0.841 & 1.192 & 0.614 & 1.714 \\
2014 & 1.000 & 1.000 & 0.947 & 1.000 & 1.056 \\
2015 & 1.000 & 1.000 & 1.005 & 1.000 & 0.995 \\
2016 & 1.002 & 1.000 & 1.051 & 1.000 & 0.952 \\
$2000-2016$ Mean & 1.030 & 0.978 & 1.037 & 0.955 & 1.083 \\
$2000-2016 S D$ & 0.035 & 0.063 & 0.085 & 0.102 & 0.175 \\
\hline
\end{tabular}

From Table 2, the average value of China's QEGI from 2000 to 2016 was 1.030, indicating an average increase of 3.0\% per year; From the decomposition of the QEGI, one can note that the largest contribution to the QEG was GSTC, followed by GPTC. GSEC and GPEC have hindered the QEG. Hence, the GSTC and GPTC are the main driving forces for improving the QEG.

A possible explanation is that China has a latecomer advantage of development in choosing the way of technological progress. First, the purchase of equipment and technological patents is embedded in capital investment to achieve technological progress, thereby improving the quality and efficiency of economic growth. Second, China's human capital has continuously accumulated, and its quality has continuously developed. In 2000, the number of college graduates was at 1.07 million, and in 2016 the figure was at 7.65 millions. With the continuous advancement of the human capital structure, the GSTC and GPTC have gradually emerged to enhance the QEG. Therefore, from the above results, we conclude that China's economic growth is not only an expansion in quantity, but also an improvement in quality. 


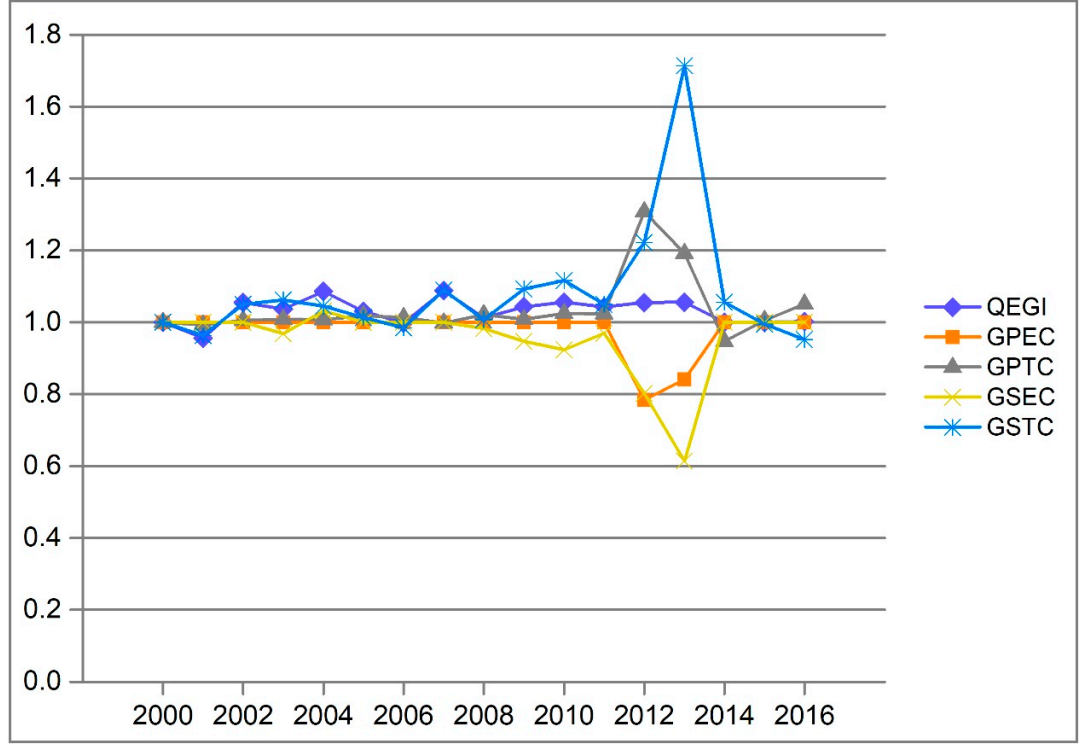

Figure 1. Trends in the QEGI and decomposition from 2000 to 2016.

\subsection{Measurement and Analysis of Provincial QEGI in China}

In order to analyze the characteristics and differences of the QEG in various provinces and regions, the changes in the QEGI, GPEC, GPTC, GSEC, and GSTC for the 30 selected provinces in China from 2000 to 2016 are calculated and decomposed. The specific results are shown in Table 3 and Figure 2.

Table 3. QEGI and decomposition by provinces from 2000 to 2016.

\begin{tabular}{|c|c|c|c|c|c|}
\hline Province & QEGI & GPEC & GPTC & GSEC & GSTC \\
\hline Beijing & 1.094 & 1.006 & 1.064 & 1.001 & 1.022 \\
\hline Tianjin & 1.226 & 1.000 & 1.157 & 1.049 & 1.009 \\
\hline Hebei & 1.362 & 1.018 & 1.073 & 0.979 & 1.273 \\
\hline Shanxi & 1.023 & 0.999 & 0.877 & 1.091 & 1.070 \\
\hline Inner Mongolia & 0.838 & 1.000 & 0.870 & 1.000 & 0.963 \\
\hline Liaoning & 0.897 & 1.014 & 0.924 & 0.986 & 0.972 \\
\hline Jilin & 0.820 & 0.999 & 1.091 & 1.000 & 0.752 \\
\hline Heilongjiang & 0.821 & 1.053 & 0.969 & 0.998 & 0.805 \\
\hline Shanghai & 2.068 & 0.999 & 0.967 & 1.001 & 2.139 \\
\hline Jiangsu & 1.215 & 0.999 & 1.094 & 0.918 & 1.211 \\
\hline Zhejiang & 1.414 & 1.000 & 1.265 & 0.963 & 1.161 \\
\hline Anhui & 1.144 & 1.002 & 1.128 & 1.001 & 1.010 \\
\hline Fujian & 0.888 & 1.035 & 0.929 & 0.995 & 0.928 \\
\hline Jiangxi & 0.837 & 0.993 & 0.904 & 1.006 & 0.926 \\
\hline Shandong & 1.230 & 1.000 & 1.146 & 0.923 & 1.163 \\
\hline Henan & 1.165 & 1.006 & 1.165 & 0.987 & 1.007 \\
\hline Hubei & 1.147 & 1.004 & 1.134 & 1.001 & 1.007 \\
\hline Hunan & 1.168 & 1.001 & 1.171 & 1.000 & 0.996 \\
\hline Guangdong & 1.191 & 0.999 & 1.063 & 0.897 & 1.249 \\
\hline Guangxi & 1.225 & 1.019 & 1.157 & 0.984 & 1.056 \\
\hline Hainan & 1.391 & 1.161 & 1.129 & 0.859 & 1.234 \\
\hline Chongqing & 1.259 & 0.937 & 1.150 & 1.064 & 1.098 \\
\hline Sichuan & 1.149 & 1.006 & 1.107 & 1.031 & 1.000 \\
\hline Guizhou & 0.902 & 1.000 & 1.031 & 0.827 & 1.058 \\
\hline Yunnan & 1.210 & 0.839 & 1.214 & 1.271 & 0.935 \\
\hline Shaanxi & 1.181 & 0.996 & 1.125 & 1.004 & 1.051 \\
\hline Gansu & 0.779 & 1.000 & 1.036 & 0.756 & 0.995 \\
\hline Qinghai & 0.787 & 0.873 & 1.054 & 1.107 & 0.772 \\
\hline Ningxia & 1.399 & 1.000 & 1.222 & 1.000 & 1.145 \\
\hline Xinjiang & 1.040 & 1.000 & 0.971 & 0.970 & 1.104 \\
\hline Eastern & 1.270 & 1.021 & 1.074 & 0.961 & 1.215 \\
\hline Central & 1.016 & 1.007 & 1.055 & 1.010 & 0.947 \\
\hline Western & 1.070 & 0.970 & 1.085 & 1.001 & 1.016 \\
\hline Mean & 1.129 & 0.999 & 1.073 & 0.989 & 1.070 \\
\hline SD & 0.263 & 0.052 & 0.106 & 0.090 & 0.239 \\
\hline
\end{tabular}




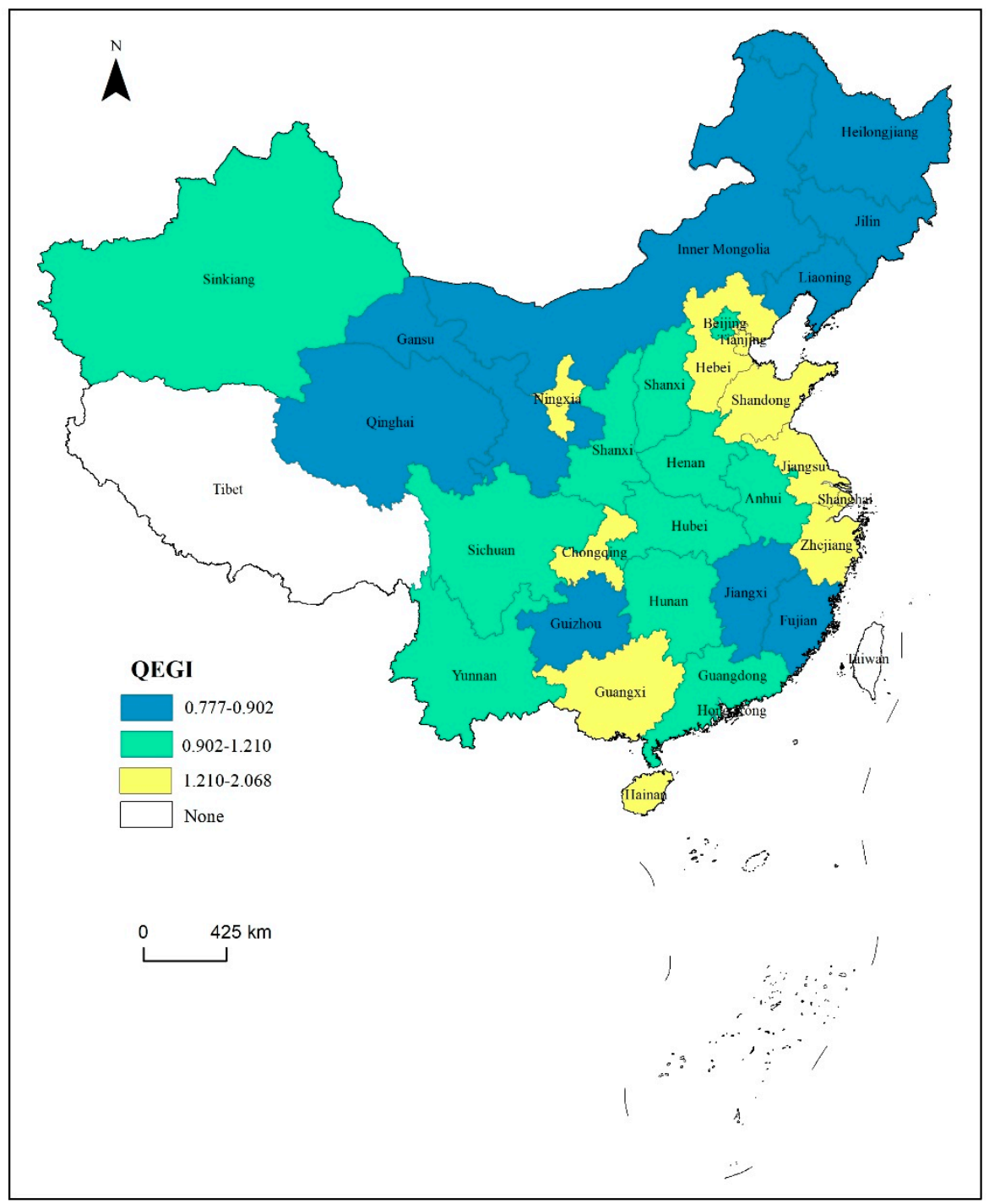

Figure 2. The regional QEGI from 2000 to 2016.

From the changes between the three major regions, the average value of the QEGI for eastern provinces was 1.270 from 2000 to 2016, indicating that the QEG in the eastern region has significantly improved. The figure for the central region was 1.016, implying a slight improvement for the QEG. For the western region, the value was lower than that of the eastern region and higher than that of the central region. The overall performance exhibits a trend of the eastern to western to central regions, from high to low.

From the decomposition, there are two factors that cause the greatest difference in the QEG between regions. The first one is the GSTC. The rank ordering of the GSTC is from the eastern to western to central regions from high to low. The second one is the GPTC, ranked from the western to eastern to central regions. This implies that the improvement of the QEG in the eastern regions is not only seen through the introduced advanced technology and independent innovation, but is also observed from the increased effect of returns to scale brought by technological progress.

Although the GPTC in the western region is larger than that in the eastern region, the GSTC is lower. As a result, the QEG in the western region is relatively backward. The GPTC and the GSTC in the central region are behind the eastern and western regions. The gap between the GSTC and GPTC is an important reason for the quality gap of regional economic growth. 
There is little difference in the GPEC and GSEC between the three regions. The GPEC of the eastern region increased by $2.1 \%$ from 2010 to 2016. The corresponding figure for the central region remained almost unchanged, and it decreased by $3.0 \%$ in the western region. The degree of resource input and output of the three regions approaching the production frontier is low, that is, the efficiency of the economic organization is low.

The GSEC increased by $1 \%$ in the central region, remained almost unchanged in the western region, and decreased by $3.9 \%$ in the eastern region. Hence, the investment scale of the three regions moved to the equilibrium point of return to scale. The main reason for the decline of the GSEC in the eastern region is due to the characteristics of excessive agglomeration, which led to the decline of the scale economy efficiency. Particularly, Tianjin, Hebei, Liaoning, Jiangsu, Zhejiang, etc. are among the provinces with a higher degree of factor concentration.

The main reasons for the slow improvement of the GSEC in the central and western regions include resource-oriented regions such as Shaanxi Province, a lower education level, a lower education investment, a lower human capital stock such as in Gansu and Ningxia Provinces, the enhancement of a constrained GSEC in agglomerations of advanced production factors, and a lower configuration efficiency of advanced elements.

From the perspective of the QEGI for each province or region, the QEGIs of 21 provinces were all above 1, indicating that the QEG improved, while the figures for Liaoning, Fujian in the eastern region, Jilin, Heilongjiang, Jiangxi in the central region, and Guizhou, Gansu, Qinghai, and Inner Mongolia in the western region were below 1, showing that the QEG declined in these provinces. The three provinces with the highest QEG indexes were Shanghai, Zhejiang, and Ningxia.

However, factors that improved the QEGI were different between provinces. Shanghai had a lower ratio of public safety expenditure, lower average intensity of industrial pollution, and higher human capital accumulation effect, and hence, the improvement of the QEG was driven by the GSTC. Zhejiang's GDP ranked at the forefront, with a larger investment, and the improvement of the QEG was driven comprehensively by the GPTC and the GSTC, but the GSEC was the main factor hindering further improvement of the QEG.

Ningxia had a lower GDP, but the growth rate of the capital stock and medical personnel led in the forefront of the country. The GSTC was the main factor boosting the QEG in Ningxia. Qinghai had a larger amount of sulfur dioxide emissions, a higher intensity of industrial pollution, and a lower input of human capital, and these reasons caused the deterioration of the GPEC and GSTC. Gansu ranked last in the QEGI. The higher emission of sulfur dioxide and the higher intensity of industrial pollution in Gansu lowered the GSEC and GSTC for all to under 1, and these are the reasons explaining the decline of the QEG.

\section{Conclusions, Policy Implications, Research Limitations and Future Research}

\subsection{Conclusions}

In this paper, we proposed to utilize the input-output efficiency of economic growth as a criterion to evaluate the QEG, and selected the GML index method to assess the QEGI and factor decomposition for China from 2000 to 2016. We now draw some conclusions.

(1) The QEGI was improved significantly from 2000 to 2016 from 1 to 1.002 , a $0.2 \%$ increase. Hence, China's economic growth is not only a quantitative expansion, but also a qualitative improvement. The biggest contribution to the improvement of the QEG is the GSTC, followed by the GPTC, while the GPEC and GSEC have no significant effect on improving the QEG. The QEG varied among the three regions, and its ordering ranked from the eastern to western to central regions, from high to low.

(2) The GPEC and GSEC were the main factors restricting the improvement of the QEG of China. The QEG of China is in a state of technical inefficiency and scale inefficiency, but the technical efficiency is constantly improving. From the perspective of regions, the technical efficiency in the eastern region is on the rise, and the technical efficiency of the central region is also increasing, but the growth rate is 
lower than that of the eastern region. The technical efficiency of the western region is lower, and the growth is slower. These results on the technical efficiency of the QEG in the three regions match with their respective social and economic conditions. The gap between provinces, regarding the technical efficiency, is narrowing.

(3) The reasons for the lower QEG in China's provinces include not only technology inefficiency and scale inefficiency, but also a higher emission of sulfur dioxide, higher intensity of industrial pollution, increased unintended output, and decrease of human capital investment.

\subsection{Policy Implications}

(1) In the future, it is recommended to expand predominately the market, strengthen the role of the market mechanism, adjust the investment structure to reduce the loss of GSEC, continue to innovate the market organization, and increase investment in human capital to boost the GPEC.

(2) The government and enterprises should strengthen technological innovation and technology import, and enhance the level of independent innovation and the ability to absorb and digest new technologies, so as to achieve the progress of the GPEC and GSEC.

(3) The government should engage environmental protection and social security management, and lower various economic costs in order to accomplish the goal of bolstering "real economic growth" and realize the unity of quantity, quality, and efficiency.

(4) The government should strengthen investment in basic public infrastructures and gradually improve the capacity of basic public services, including education, health care, employment, public security, and environmental protection, especially in the northwest regions, so as to achieve equalization with the eastern region; this implies policies of migration and poverty alleviation in the ecologically fragile, uninhabitable, and poverty-stricken areas.

(5) The government should coordinate the handling of the relationship between economic development and environmental protection, and increase investment in environmental pollution control and ecological restoration. It should actively apply advanced production and environmental protection technologies at home and abroad to improve energy efficiency and reduce environmental pollution actively. At the same time, attention should also be paid to the use of pollution control and ecological restoration technology to improve the capacity of pollution control and ecological environment restoration.

(6) The government should clearly stipulate the proportion of R\&D expenditures in fiscal budgets at all levels. As the main body of R\&D investment, enterprises need to rely on the relevant governmental incentive policies, consciously increase $R \& D$ investment, and improve the innovation ability and competitiveness of enterprises. Universities and scientific research institutes should strengthen their cooperation with enterprises and governments in the fields of production, learning, and research, and urge the government to strengthen $R \& D$ investment as a recognition of the added economic and social benefits resulting from $R \& D$ research results.

\subsection{Research Limitation and Future Research}

While we have developed an extended TFP method for measuring the QEG in China, this research may face some limitations. First, some input-output indicators are not considered, such as the distribution of opportunities, environmental sustainability, globalization, and the subjective feelings of residents (e.g., government satisfaction, education, and medical satisfaction). This may make the indicator system lack systemicity. A refinement of the index system with the inclusion of more influencing factors will be a further step to expand and achieve a more comprehensive and scientific assessment system.

Second, the calculation and structural decomposition of the QEGI have revealed the temporal and spatial evolution laws of the QEG in China's provinces, as well as the characteristics of the influencing factors of the QEGI. However, the present work is largely a qualitative analysis on the influencing 
mechanism of the four influencing factors, GPEC, GPTC, GSEC and GSTC, and future work will focus on conducting an in-depth quantitative analysis.

Third, the focus of this paper is to calculate the quality indices, one by one, of economic growth (QEGI) for 30 provinces and regions in China from 2000 to 2016, decompose the QEGI into four components, and analyze the impact of the four components on the change of the QEGI. The present work does not include a spatial evolution analysis and impact mechanism analysis between provinces and regions. Future work should for example analyze the spatial auto-regression and impact mechanism of the QEG in China and provide a corresponding reliability test.

Author Contributions: S.R. conceived and performed the research; J.L. participated in data collection and paper development. T.W. and G.W. conceived and made valuable comments and suggestions on the writing and revision of the paper. All authors have read and agreed to the published version of the manuscript.

Funding: This research was funded by the Key Research Foundation of Humanities and Social Sciences of the Ministry of Education of China (16JJD790046).

Acknowledgments: The authors are grateful to Baoping Ren at the School of Economics \& Management, Northwest University of China for the generous comments and inspiration, which greatly improved the manuscript. The authors also thank the anonymous referees for their comments.

Conflicts of Interest: The authors declare no conflict of interest.

\section{References}

1. Kamayev, H.D. Speed and Quality of Economic Growth, 1st ed.; Hubei People's Press: Hubei, China, 1983.

2. Liu, Y. An analysis of the effectiveness of China's economic growth. Thinking 2002, 4, 30-33.

3. Liu, H.; Zhao, Y.; Zhang, C. A study the relationship between "Averaging" human capital and the China's economic growth quality. Manag. World 2004, 20, 15-21.

4. Kang, M. Factor analysis and quality evaluation for economic growth with investment-growth model. J. Quant. Tech. Econ. 2006, 23, 153-160.

5. Mohsin, S.K.; Zuliu, H. Why is China growing so fast? IMF Staff Pap. 1996, 44, 103-131.

6. Wang, X. Sustainability of China's economic growth and institutional changes. Econ. Res. J. 2000, 7, 3-15, 79.

7. Wang, X.; Fan, G. Sustainability of China's Economic Growth, 1st ed.; Economic Science Press: Beijing, China, 2000; pp. 46-53.

8. Chow, G.; Lin, A.L. Accounting for economic growth in Taiwan and mainland China-a comparative analysis. J. Comp. Econ. 2002, 30, 507-530. [CrossRef]

9. Yi, G.; Fan, G.; Li, Y. A theoretical analysis on economic growth in China and total factor productivity. Econ. Res. J. 2003, 8, 13-20, 90.

10. Zhang, J.; Shi, S. China's economic total factor productivity change: 1952-1998. World Econ. Forum. 2003, 17-24.

11. Yan, P.; Wang, B. Technical efficiency, technical progress \& productivity growth: An empirical analysis based on DEA. Econ. Res. J. 2004, 12, 55-65.

12. Wang, B.; Yan, P. Productivity and efficiency in China: 1952-2000. J. Quant. Tech. Econ. 2006, 23, 22-30.

13. Zheng, J.; Hu, A. An empirical analysis of provincial productivity in China (1979-2001). Economics 2005, 1, 263-296. [CrossRef]

14. Wang, Z.; Gong, L.; Chen, Y. China's regional differences in technical efficiency and the decomposition of total factor productivity growth (1978-2003). Soc. Sci. China 2006, 2, 55-66, 206.

15. Zhu, C.; Yue, H.; Li, T. An empirical study on economic growth efficiency and affecting factors in China: 1985-2007. J. Quant. Tech. Econ. 2009, 9, 52-63.

16. Shadbegian, R.J.; Gray, W.B. Assessing multi-dimensional performance: Environmental and economic outcomes. J. Product. Anal. 2006, 26, 213-234. [CrossRef]

17. Wang, B.; Wu, Y.; Yan, P. Environmental efficiency and environmental total factor productivity growth in China's regional economies. Econ. Res. J. 2010, 45, 95-109.

18. Wang, W.; Fan, D. Influential factors and convergence of total factor energy efficiency in China based on the Malmqulist-Luenberger index. Resour. Sci. 2012, 10, 1816-1824. 
19. Qi, Y. Measurement and decomposition of China's total factor productivity growth under carbon emission. J. Ind. Technol. Econ. 2013, 5, 137-146.

20. Tu, Z.; Liu, L. Efficiency evaluation of industrial sectors in China accounting for the energy and environment factors: Based on provincial data by a SBM approach. Econ. Rev. 2011, 2, 55-65.

21. Chen, P.; Wang, J. Analysis of the causes of the differences in the measurement of total factor productivity in China-based on DEA. Contemp. Econ. 2013, 1, 115-117.

22. Zheng, Y. Again knowledge of total factor productivity. J. Quant. Tech. Econ. 2007, 9, 3-11.

23. Thomas, V.; Mansoor, D.; Ashok, D.; Ramon, E.; López, D.K.; Nalin, K.; Yan, W. The Quality of Growth; Athens Center of Ekistics: New York, NY, USA, 1999.

24. Barro, R.J. Quality and Quantity of Economic Growth; Working Papers; Central Bank of Chile: Santiago, Chile, 2002.

25. Liu, S. On the development with better-fast growth. Econ. Res. J. 2007, 6, 4-13.

26. Ren, B. Economic growth quality: Its principle analysis, basic propositions and ethical principles. Acad. Mon. 2012, 2, 63-70.

27. Ren, B.; Li, J. To realize the unity of the quantity, quality and efficiency of economic growth. J. Northwest Univ. 2013, 1, 110-115.

28. Chao, X.; Xi, K. Measuring quality of economic growth of China. J. Quant. Tech. Econ. 2009, 6, 75-86.

29. Liu, H.; Zhang, C. An empirical study on the inconsistency between the quality improvement and scale expansion of China's economic growth. Econ. Sci. 2006, 2, 13-22.

30. Zhao, Y.; Zhang, C.; Liu, H. Comprehensive evaluation of China's economic growth during transition period. Jilin Univ. J. Soc. Sci. Ed. 2006, 3, 27-35.

31. Ma, J.; Shen, S. The preliminary study of economy growth quality. Res. Financ. Econ. Issues 2007, 3, 8-23.

32. Chao, X.; Ren, B. The fluctuation and regional difference of quality of economic growth in China. Econ. Res. J. 2011, 4, 26-40.

33. Hailu, A.; Veeman, T.S. Environmentally sensitive productivity analysis of the Canadian pulp and paper industry, 1959-1994, an input distance function approach. J. Environ. Econ. Manag. 2000, 40, 251-274. [CrossRef]

34. Romer, P.M. Increasing returns and long-run growth. Eur. J. Political Econ. 1986, 94, 1002-1037. [CrossRef]

35. Oh, D.H. A global Malmquist-Luenberger productivity index. J. Prod. Anal. 2010, 34, 1345-1355. [CrossRef]

36. Fare, R.; Shawna, G.; Mary, N.; Zhong, Z. Productivity growth, technical progress, and efficiency change in industrialized countries. Am. Econ. Rev. 1994, 84, 1040-1044.

37. Tao, C.; Qi, Y. Spatial difference and causes analysis of total factor productivity in China. J. Quant. Econ. 2012, 1, 19-22.

38. Shan, H. Re-estimation of capital stock K in China: 1952-2006. J. Quant. Tech. Econ. 2008, 10, 17-31. 